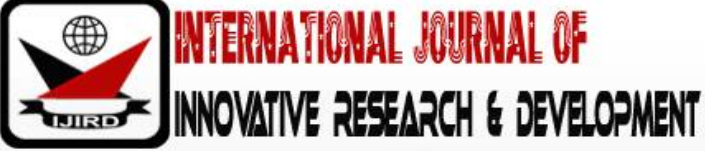

ISSN 2278 - 0211 (Online)

\section{Effectiveness of Guidance and Counselling Services in Senior High Schools at Jaman North District in the Brong Ahafo Region of Ghana}

Prince Kwame Affum
Assistant Counselor, Department of Counselling Unit,
University of Energy and Natural Resources, Sunyani, Ghana
Gordons Kojo Tawiah
Tutor, Department of St James Seminary Senior High School, Sunyani, Ghana
Prince Laryea
Lecturer, Department of Institute for Distance and e-Learning (IDeL)
University of Education, Winneba, Ghana

\begin{abstract}
:
The main aim of this study was to examine the effectiveness of guidance and counselling services in senior high schools in the Jaman North district of Ghana. Case study research design was used to study the topic. The targeted population comprised Senior High School students and guidance coordinators or counsellors. Semi-structured interview guidewas used to collect data from the students and counsellors. Purposive sampling technique was used to select all 6counsellors and convenience sampling technique was used to select 36 students who had patronized guidance and counselling services in their schools. The researchers discovered that the main problems that students faced in senior high schools were subject selection, substance abuse, relationship problems and stress. The study also discovered that guidance and counselling services were not effective in the district due to lack of trust and unavailability of the counsellors. The researchers concluded that practicing guidance and counselling coordinators in the district lacked specialized training in the profession. The researchersrecommended among other things that the Ministry of Education in collaboration with Ghana Education Serviceshould enforce policies of posting professionally trained counsellors to all senior high schools in the country.
\end{abstract}

Keywords: Guidance and Counselling, depression, substance abuse/ alcoholism

\section{Introduction}

In the Ghanaian society, Guidance and Counselling plays integral role in both teaching and learning and thus, must be given the necessary attention in all educational endeavours. Guidance and Counselling activities should be pivotal in school curriculum and must also be given the necessary attention in educational set ups to assist students. Guidance and Counselling must therefore be carefully designed and well executed at every level of the educational ladder especially at the basic school level. According to Esen (2010), it is an open secret that students in Ghana face myriad of challenges which militate against their academic, career and socio personal progress in school due to the absence of quality guidance and counselling services. Looking at the African continent-including Ghana and Nigeria (West Africa), Uganda (East Africa), Pretoria and Nkangala district (South Africa), the issue of guidance and counselling is very crucial. Okobiah (2006) opines that in Western Nigeria, various findings suggest that major factors including issues with both time management and adequate concentration calls for guidance and counselling in our societies. Goss (2014) proposes that in Africa, guidance services should be established in institutions such as Catholic Seminaries not only purely for the provision of personal emotional care but also directed towards the provision of support to address practical issues.

Casey (2017) asserts that the school is a miniature African society and as such, life in the school must reflect the life of the African people among whom the school is situated. The school as an educational institution seeks to help and develop the totality of the individual to fit holistically into the society. The goal of guidance and counselling in educational settings therefore, is synonymous with that of education since Guidance and Counselling seeks to ensure the total wellbeing of the individual in relation to the society (Mensah \&Affum, 2016). The Western models of guidance and counselling typically places significant emphasis on the client disclosing personal information often particularly private and sensitive information-so that the practitioner can provide help, often by further explaining details and nuances of that information in ever increasing depth and detail (Alonge, 2010). This ignores useful sources of help derived from traditional cultural practices and furthermore, can place an unrealistic expectation of openness and engagement style on clients that can combine to create significant barriers to effective helping (Okobiah, 2006). This is far from suggesting of cause, that contributions cannot be made by Western models. Affum, Kuranchie and Mensah (2016) suggest that traditional practices 
of guidance and counselling can adopt skills and techniques from the Western approach to make the helping process more efficient in the African context.

Most students in second cycle institutions fall within the adolescent phase of development and as such suffer difficulties from the various emotional and psychological strains, stresses and anxieties associated with their education and careers. Mirigo (2005) was of the view that it is very important that succour is given to such students to help them know themselves, their capabilities, aptitudes, interests, needs, strengths and limitations. The rationale for this allimportant study is to explore the problems Senior High School students face in the Jaman-North District in the Brong Ahafo Region of Ghana and how guidance and counselling is used to effectively help them deal with their problems.

\section{Methodology}

Using the interpretivist-qualitative research approach the researchers conducted this study by employing case study research design. This assisted the researchers to do an in-depth study into the problems of senior high school students and the effectiveness of guidance and counselling in the schools by exploring the opinions, preconceived notions and ideologies of the researched in their own socio-cultural context.

\subsection{Sample and Sampling Procedure}

The researchers used purposive sampling technique to select all six (6) counsellors in the six Senior High Schools within the Jaman North District in the Brong Ahafo region of Ghana. The researchers also used convenience sampling technique to sample students who had patronised Guidance and counselling services in their respective schools, this was achieved with the assistance of the counsellors who sought permission first from their clients and disclosed the identities of only those who agreed to part-take in the study. Through convenience sampling technique, the researchers were able to sample 36 student participants for the study.

\subsection{Instrument}

The researchers used semi-structured interview guide to collect data from counsellors and students in Jaman North district in the Brong Ahafo region of Ghana. This instrument allowed the researchers to collect in-depth data from the participants. It also allowed the researchers to maintain focus on the main objectives of the study which collecting data. The semi structured interview guide gave the researchers the chance to probe further for clarity and understanding. In other words, the semi-structured interview allowed the researchers to use probes and prompts as and when necessary.

\subsection{Data Analysis}

Improper statistical analyses distort findings, mislead casual readers and may negatively influence public perception. In order to avoid these, after all the data had been collected through interviews, they were analysed using thematic data analysis approach. In utilising the thematic analysis procedure, we organized the data and 'immersed'ourselves in the data by listening to the recorded audio over and over again; we then transcribed it from audio to written text, grouped it into themes and coded the data. We ensured that the codes were appropriate through consensual coding technique. This allowed each member of the research team to assign codes to each of the transcripts independently and later we compared the assigned codes. For example, a student's comment such as "I had a problem in my romantic relationship that was a affecting my academic achievement. The counsellor was very helpful" was coded "Personal Problems". Counsellors' comments such as "we usually group them and give them talks on trending issues that affect them" was coded "Interventions". To ensure anonymity, the counsellors from this qualitative study who were interviewed were coded PGC1-PGC6 connoting Participating Guidance Coordinator 1 to Participating Guidance Coordinator 6 while the students who were interviewed were coded PS 1- PS 36 connoting Participating Student 1 to Participating Student 36. Additionally, descriptive statistics was used to analyze some quantifiable data that emerged from the interview with the students.

\section{Results and Discussions}

The details of the results analysed from the responses obtained from both respondents and participants are shown here. The data were presented using descriptive statistics and thematic analysis. The findings are organized according to the objectives of the study. The purpose of the study was to find out the significance of guidance and counselling in senior high schools. It sought to bring out the problems facing adolescents in school, the importance of guidance and counselling, its effectiveness and how to improve the service in senior high schools. This section attends to the topic accordingly.

\subsection{Problems Facing Adolescents in Senior High Schools}

The investigators tried to identify the problems of adolescents in senior high schools and by so doing, discovered that majority of the students had problems with the school curriculum especially immediately after they gain admission into the senior high schools. Most of the students sampled seemed to indicate that they have problem with subject selection. The students factually gave out the following responses;

"My parents asked me to come and read science but I am not good in calculations. So, I decided to pay heed to what my parents want without knowing exactly what it entails as course".PS 1

"I wanted to read history as a course; it was in the school a friend told me history was not a course but an individual subject in the general arts department. So, it was a mess for me". PS 3 
"I entered senior high school without exactly knowing what to do. I could not even select one subject on my own. I copied blindly from my friends whether leading me to a purposeful end or not". PS 6

Some of the students also revealed that the courses that they are currently pursuing are not related to their future aspirations. The following are some of the responses they gave;

"I had no idea of what my course will lead me to. I knew very well that in future I will be a pilot but mistakenly I am a business student. Please sir I have already caused the blander". PS 9

"Little did I know that what I will do in future have direct bearing on the course or subjects I am reading now in school. So, I chose my course based on what I can conveniently read not what will give me job in future". PS 36

"I am just happy to be here (in school) with my friends. I know definitely that in future I will get work to do. The future is too far off to be thinking of what to do then. PS 18

The findings above seem to suggest that most students are not adequately informed about the school curriculum prior to their entry into senior high schools. The findings also indicate that some students have their educational paths being different from their career paths. There were also few students who indicated that their choice of program-to-bestudied was influenced by their parents and friends. Pereira (2008) revealed that problems of adolescents are more among the nuclear families, especially where both the parents are working.

During the interviews with the counsellors/coordinators, they were asked about some personal and social problems students face in senior high schools. Below were some responses:

"Most parents are not supportive in their wards education. They sometimes beg house Masters and Mistresses to release their wards from the boarding house so that they can attend funerals and other occasions which do not really help their studies". PGC1

"Their problems start from the house and they bring them to the school. Some students come to school already exhausted and depressed and their facial expression shows that they are not ready to cope. Few of them take alcohol occasionally especially sporting periods. Some students also have problem with authority" PGC2

"Some the students come to school and for the first period they are already sleeping which clearly suggests that their problems are from the house because of either they work too much or they do not sleep early. There are also cases of students who have emotional problems because they are involved in romantic relationships".PGC6

Most of the counsellors seemed to indicate that one major problem with adolescents in senior high school stress and depression. This is in line with Hang and Van (1998) who concluded that adolescent depression is really a serious problem with common symptoms that anyone can suffer from in daily life. Adegoke (2003) asserts that the willingness of adolescents to engage in risk taking behaviours such as being sexually active, dropping out from school, abusing substance, violence, alcoholism and smoking cigarettes is normative. Adegoke's argument concur with the responses of the counsellors

\subsection{Effectiveness of Guidance and Counselling in Senior High Schools}

Effective counselling programs are important to the school climate and a crucial element in improving student achievement. Following is a collection of sources that address the effectiveness of school counselling and other student support services, including their contribution to the personal and academic success of students. For Mugenda and Mugenda (1999), reviews of the research on school counselling show that the services of school counsellors have a positive effect on children.

\begin{tabular}{|c|c|c|}
\hline Responses & Frequency & Percentage \\
\hline Strongly Agree & 2 & 5.6 \\
\hline Agree & 7 & 19.4 \\
\hline Disagree & 9 & 25 \\
\hline Strongly Disagree & 18 & 50 \\
\hline Total & 36 & 100 \\
\hline
\end{tabular}

Table 1: Students Statistics on Effectiveness of Guidance and Counselling in Senior High Schools

Source: Field Data, 2018

Table 1 revealed that students felt that there are little or no counselling services in schools to assist them. Results showed that only $9(25 \%)$ of the student sample agreed that there are available counselling services for them in their schools. Meanwhile, 27 (75\%) proved that there is ineffectiveness of the guidance and counselling programs to assist them $\mathrm{n}$ their respective schools.

However, in an attempt to determine the effectiveness of guidance and counselling services in senior high schools, the researchers discovered from the interview transcripts that majority of the students sampled believed the counsellors in their schools were not trustworthy. They revealed the following;

"For me I have been to the school counsellor twice and there has been no change in my situation. I am a weak student but after seeing the counsellor, nothing really changed. To make matters worse, the entire world knows what I discussed with her.PS 4 
"I have a little trust in our school counsellor because I told him I was having an intimate sexual relationwith my partner and that which I needed help with were about my relationship. The next few of days, I realized that all his examples in class were directly from the discussion I had with him".PS 20

"From the experiences shared by colleagues, I do not feel like going to see the counsellor though I have serious challenges" PS 29

The above findings contradict the assertions of Mugenda and Mugenda (1999) who assert that the services school counsellors have a positive effective on children. Contrary to the above assertion, the students believed the counsellors in the schools at Jaman North have little or no impact at all in their lives.

Asked whether counsellors were easily accessible and available in the schools, the students revealed that it is very difficult to meet their counsellors.

"For more than three occasions I have been to him personally but met his absence. So, I have stopped seeing him. He is not always available". PS 31

"Our counsellor is not punctual at his office. It is very rare to find him in the office. The day you will encounter him too, he is in a rush to go elsewhere. The day you have a problem to share is the day his office is closed" PS 34

"You go and his other colleagueteachers will tell you he is not around. This often happens". PS 22

The researchers tried to find out if students found guidance and counselling services rendered at their various schools helpful. Students' responses seemed to indicate that because the counsellors were not easily accessible and available, they do not benefit from the services.

"Little do we see the person; how then can his services be helpful to us? Our problems are always there with us and we are coping on our own". PS 11

"It isn't that the services do not help us, we do not even get the service. It is probably better this way because even when we get him to attend to us, our problem eventually becomes the talk of the town". PS 15

The responses seem to confirm the responses of other student participants who earlier revealed that it is difficult for them to meet their school counsellors. For them, since they barely have access to the counsellors, they do not find the service helpful. PS 15 added that they are better off not meeting their counsellors because their problems were not safe with them. PS 15 reechoes the concerns of many other students who also believed their secrets were not safe with their counsellors. Mensah and Affum (2016) explain that confidentiality is the hallmark of counselling. This implies that professional counsellors do not breach confidentiality of their clients unless the information being disclosed poses a threat to the life of the client or others. Ackummey (2003) however asserts that in the school setting, one cannot be entirely confidential. For her, there are some cases that need consultation with some school authorities.

The counsellors were also interviewed about the effectiveness of the services they provided to students. Majority of the school counsellors revealed that counselling services were not effective in their schools. Below are some of their responses;

"It is not all that effective since I have been moving from class to class talking about disciplinary issues simply because there is no office. Any little chance is well utilized and so that is my biggest challenge now". PGC3.

"To strictly talk about the effectiveness of the service is not worthwhile in the sense that the students do not even come to me with their problems. I am only making an attempt to fit into the shoes of a professional counsellor. Besides, there is no office to operate from". PGC4.

"Guidance and counselling services are not effective at all in this school. I sometimes have to force students to come for counselling." PGC 2

From the interviews, it is clear that guidance and counselling services are not effective in the selected schools in Jaman North district. A study conducted by Kigin (2001) indicates that high school counsellors influenced their students' future plans by encouraging them to cope and have high expectations.

\subsection{Improving Guidance and Counselling Services in Senior High Schools}

The researchers identified some challenges with the guidance and counselling services offered in senior high schools within Jaman North district as reported by students and the school counsellors themselves. The researchers therefore investigated the perspectives of the counsellors to determine what can be done to improve the services they render in schools. Below are some of the responses of the counsellors:

"There is no office to operate from and because of that it is difficult to maintain privacy and confidentiality sometimes". PGC 4

"There are very limited resources available to counsellors in this district. Organizing seminars require funds especially when specialists are invited to facilitate. Also, we need offices; we usually meet students in staff rooms and sometimes under trees". PGC 6

"Sometimes it is difficult to know what to do with some cases we get and this is only because most of us practicing here as counsellors are not professionally trained." PGC 2

The responses here suggest that coordinating counsellors at Jaman North district have a major challenge with logistics and because of that they are not able to practice comfortably and offer the best services. This probably explains why students reported problems of confidentiality and trust. It also probably explains why students and counsellors revealed that guidance and counselling services in Jaman North district are not effective. 


\section{Conclusions and Recommendations}

Based on the findings of this study, it can be concluded that the major problems facing the students as far as guidance and counselling is concerned in the Jaman North district are in the areas of subject selection, courses relating to their future career, depression and substance abuse/alcoholism and romantic relationship problems. The researchers recommend the need of getting professional counsellors/coordinators to handle all problems especially depression and poor academic performance in all senior high schools. This should be a core mandate of the Ministry of Education and Ghana Education Service. Professional counsellors will know how exactly to handle students especially those with emotional and psychological problems that stem from alcoholism/ substance abuse and personal social problems.

The study again concluded that guidance and counselling services are not effective in schools since students do not trust the counsellors. It may also be concluded that guidance and counselling are not so effective because the coordinators do not seem to know how to go about handling sensitive cases. Also, it may be concluded that unavailability and inaccessibility of counsellors make guidance and counselling services ineffective in senior high schools at Jaman North District of Ghana. The researcher recommends that Ghana Education Service and Ghana Psychology Council implement a strict monitoring and supervisory mechanisms to observe the activities of counsellors in senior high schools. This will abate the problem of availability and accessibility of counsellors in schools. Also, Ghana Education Service should consider reducing credit hours allocated to counsellors for teaching activities-this will also help make them more accessible and easily available.

For guidance and counselling services to be effective in schools and other institutions for that matter, there is the need to adhere to the best practices and code of ethics relating the profession. This implies that the regulatory body of psychologists in Ghana, the Ghana Psychology Council must ensure that high standards of the profession are maintained through regular appraisals and evaluations of counsellors in the country.

There is also the need for regular training and development programs initiated by Ghana Education Service, Head teachers, associations like the Ghana National Association of Certificated Counsellors (GNACC) and Ghana Psychological Association (GPA) to help groom and mold practitioners into ideal professional counsellors. This will help practitioners to adhere to common ethical principles of counselling especially, confidentiality.

\section{References}

i. Ackummey, M. A. (2003). Organisation and Administration of a School Guidance Programme. Accra: Media Graphics and Press LTD

ii. Affum, P. K., Kuranchie, A. \& Mensah M. K. (2016). The Place of Theory in Traditional Guidance and Counselling in Modern Ghanaian Cultures. African Education Research Journal, 4(3): 131-139.

iii. Adegoke, A. A. (2003). Adolescents in Africa; revealing the problems of teenagers in contemporary African society. Ibadan: Hadassah Publishing

iv. Alonge, P. F. (2010). Essentials of Research Methods and Designs for Educators. Lagos: Bolabay Publications.

v. Bedu-Addo, P. K. A. (2016). Guidance and Counselling 'Unmasked'. (3' Ed.). Accra: Approached Ghana Ltd.

vi. Casey, D. R. (2017). Theories in Guidance and Counselling. Nairobi-Kenya: MaizonGatc

vii. $\quad$ Drury, L. (2006). Modern Methods of Data Analysis. New Delhi: Sage Publications.

viii. Esen, A. (2010). Counselling the Less Endowed in Secondary Schools. Nigeria: Ibom State University.

ix. Goodyear, S. (2006). Measurement and Evaluation in Research. New York: John Wily and Sons.

x. Goss, Y. (2014). Students Manage Academics During Trauma. New York: College Press.

xi. Kigin, D. (2001). Reflections on School Career Education in Hong Kong. Asian Journal of Counselling. Retrieved: 03-02-2018. From http:// www. Asianjor// 12.

xii. Kusi, H. (2012). Doing Qualitative Research: A Guide for Researchers. Accra New-Town: Emmpong Press.

xiii. Mensah, M. K. \&Affum, P. K. (2016). A comprehensive guide to effective guidance and counselling. Kumasi-Ghana: Greatimpression Ltd.

xiv. Mirigo, N. N. (2005). An Investigation into the State of Guidance and Counselling in Secondary Schools. Unpublished PGDE Project, Kenyatta University. Nairobi.

xv. Moula, J. M. (2011). Factors Affecting Guuidance and Counselling Programmes in Primary Schools. Kenya: Province Ltd-Nairobi.

xvi. $\quad$ Mugenda, O. M. \& Mugenda, A. G. (1999). Research Methods Qualitative and Quantitative Approaches. Nairobi: Act Press.

xvii. Okobiah, O. C. (2006). Concepts of Guidance and Counselling. Issues Concepts, Theories and Techniques of Guidance and Counselling Benin-City: Ethiope Publishers.

xviii. Pannoni, A. (2015). Ways High School Counsellors can help Students, Parents. San Diego: Digital producers.

xix. Pereira, S. (2008). Problems of Adolescents and Effectiveness of Counselling. Mysore University, Unpublished Ph. D. Thesis.

xx. Rafferty, M. (1999). Handbook: Educational Administration Guide for the Practitioner. Boston: Ally \& Bacon Inc.

xxi. Siegel, H. (1988). Educating Reason: rationality, Critical Thinking, and Education, New York: Routledge.

xxii. Van, P. H. (1998). Economics of Child Labour and Development. The American Economic Review. 88(6): 67-74. 